\title{
Reverberation, Sediment Acoustics, and Targets-in-the-Environment
}

\author{
Kevin L. Williams \\ Applied Physics Laboratory \\ College of Ocean and Fishery Sciences \\ University of Washington \\ Seattle, WA 98105-6698 \\ phone: (206) 543-3949 fax: (206) 543-6785 email: williams@apl.washington.edu \\ Grant Number: N00014-11-1-0428
}

\section{LONG-TERM GOALS}

Develop and experimentally test target scattering models as well as reverberation/sediment-acoustic models. Quantitatively assess the modeling approximations possible within the fidelity/speed requirements of Navy performance estimators/simulators.

\section{OBJECTIVES}

Over at least the last few decades, much of the basic research effort related to ASW has focused on low-frequency propagation (the passive problem). Meanwhile, submarine technology has forced the Navy to increase its use of (low and mid-frequency) active sonar, in which case reverberation (including clutter) limits performance. Contemporaneously, active sonar MCM efforts have extended their frequencies of operation from high down to mid-frequencies. Again, in many cases, reverberation limits performance for these MCM systems. Thus the shallow water problem of acoustic scattering from a target in a waveguide, as well as character of the associated reverberation, continues to be both an applied and basic research problem of some significance over a broad range of frequencies.

My objectives are to:

1) carry out field measurements of shallow water reverberation and target scattering in the mid-tohigh frequency range,

2) quantitatively predict these experimental results using a combination of exact finite element modeling, approximate numerical modeling, and analytical physical acoustics modeling.

3) determine the approximations possible within performance-prediction/mission-planning requirements.

\section{APPROACH}

The foundation of the reverberation and target scattering research are experiments planned for FY1314. These experiments involve measurements of target and sediment backscattering as well as reverberation. The main experiment will occur off the coast of Florida in FY13 at a shallow water, 


\section{Report Documentation Page}

Form Approved

OMB No. 0704-0188

Public reporting burden for the collection of information is estimated to average 1 hour per response, including the time for reviewing instructions, searching existing data sources, gathering and maintaining the data needed, and completing and reviewing the collection of information. Send comments regarding this burden estimate or any other aspect of this collection of information,

including suggestions for reducing this burden, to Washington Headquarters Services, Directorate for Information Operations and Reports, 1215 Jefferson Davis Highway, Suite 1204, Arlington

VA 22202-4302. Respondents should be aware that notwithstanding any other provision of law, no person shall be subject to a penalty for failing to comply with a collection of information if it

does not display a currently valid OMB control number.

1. REPORT DATE

30 SEP 2014

4. TITLE AND SUBTITLE

Reverberation, Sediment Acoustics, and Targets-in-the-Environment

6. $\operatorname{AUTHOR}(\mathrm{S})$

7. PERFORMING ORGANIZATION NAME(S) AND ADDRESS(ES)

University of Washington,Applied Physics Laboratory,1013 NE 40th Street,Seattle,WA,98105

9. SPONSORING/MONITORING AGENCY NAME(S) AND ADDRESS(ES)

3. DATES COVERED

00-00-2014 to 00-00-2014

5a. CONTRACT NUMBER

5b. GRANT NUMBER

5c. PROGRAM ELEMENT NUMBER

5d. PROJECT NUMBER

5e. TASK NUMBER

5f. WORK UNIT NUMBER

8. PERFORMING ORGANIZATION REPORT NUMBER

10. SPONSOR/MONITOR'S ACRONYM(S)

11. SPONSOR/MONITOR'S REPORT NUMBER(S)

12. DISTRIBUTION/AVAILABILITY STATEMENT

Approved for public release; distribution unlimited

13. SUPPLEMENTARY NOTES

14. ABSTRACT

15. SUBJECT TERMS

16. SECURITY CLASSIFICATION OF:

a. REPORT

unclassified b. ABSTRACT unclassified c. THIS PAGE

unclassified
17. LIMITATION OF ABSTRACT

Same as

Report (SAR)
18. NUMBER 19a. NAME OF

OF PAGES RESPONSIBLE PERSON

6 
sand bottom site. A second, more target oriented experiment will occur in FY14 in a shallow water, muddy site. A major goal of the experiments is to measure both the acoustics and the environmental conditions needed as input to models designed to predict the acoustic results. (These experiments are made possible by leveraging a combination of funds from the ONR Ocean Engineering, ONR Ocean Acoustics and SERDP Munitions Response teams.)

\section{Reverberation}

Wave theory, ray and energy transport based models of shallow water propagation and reverberation will be compared to the experimental data. The acoustic and contemporaneous environmental measurements will focus on supporting quantitative data/model comparisons in the 3-4 $\mathrm{kHz}$ range but will include data taken from 1-10 kHz.

\section{Targets-in-the-environment response (TIER)}

The target scattering experiments covered the frequency range from about 3 to $30 \mathrm{kHz}$. A variety of targets, specified by the sponsors, were placed in view of a rail/tower system that takes data at a sufficient resolution to produce synthetic aperture images of the target or, alternatively, to develop images of the target strength as a function of frequency and angle of observation. Finite element models (in combination with various physical acoustics based approximations) of the elastic response of these targets will be developed and compared to the data.

\section{Sediment Acoustics}

This effort is more model-focused with the corresponding experimental data already in hand from previous work, i.e., SAX99 and SAX04. Data from those experiments, on sediment sound speed, attenuation and scattering have indicated deficiencies in current sediment models at both low (below 3 $\mathrm{kHz}$ ) and high (above $150 \mathrm{kHz}$ ) frequencies. The approach here will be to examine two physical effects that to this point have not been introduced into the model. At low frequencies this involves the thermal conductivity of the media and at high frequencies its non-continuum nature.

\section{WORK COMPLETED}

\section{Reverberation}

We continued testing models (with various sophistication) against experimental data. In the present effort simple energy transport modeling was compared to experimental data as well as more sophisticated modeling carried out by other researchers.

\section{Targets-in-the-environment response (TIER)}

The BAYEX experiment was carried out in St. Andrews Bay (a mud environment). Data was acquired on multiple targets. A separately funded ONR effort (N00014-07-G-0557/0032) paid for the BAYEX14 experiment and data analysis. The effort within this grant is focused on modeling development and data/model comparisons. 


\section{Sediment Acoustics}

The Effective Density Fluid Model (EDFM), as expanded to include the thermal conductivity of the media at low frequencies and granularity effects at high frequencies was used as part of a study on the effects of temperature on the speed and attenuation of sound in sand.

\section{RESULTS}

Reverberation

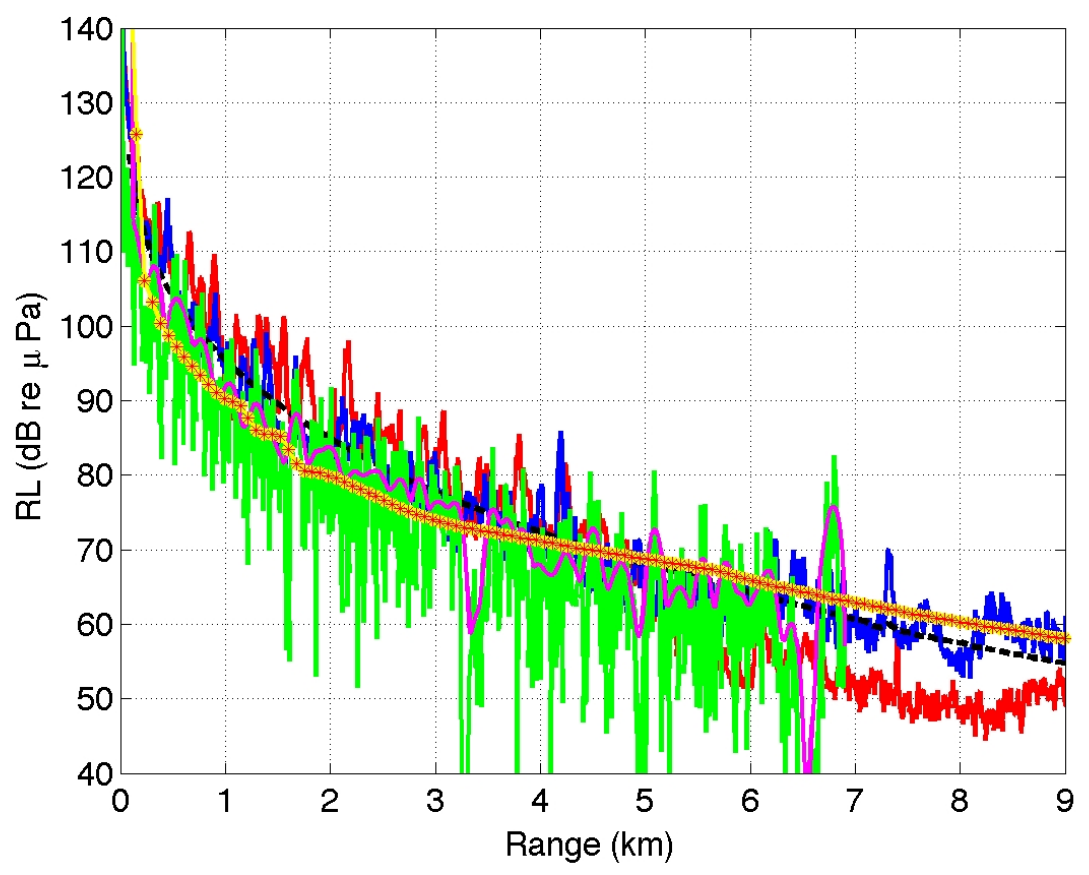

Figure 1: TREX experiment data (blue and red curves) are compared to an energy transport model (yellow line with red stars). Model used measured bathymetry, sediment and water properties, and a Lambert parameter of -27 dB. Other models -magenta line - PE (by Dajun Tang), black dashed line - GRAB (by Todd Hefner).

Figure 1 shows both experiment results from TREX13 and the results of an energy transport model for reverberation (ASPM). The model is able to capture the general background trend of the data, however, even with inclusion of local topography, is unable to capture the details. More sophisticated models, capable of using more of the environmental measurements, are being developed under separate funding by D. Tang and B. T. Hefner. 


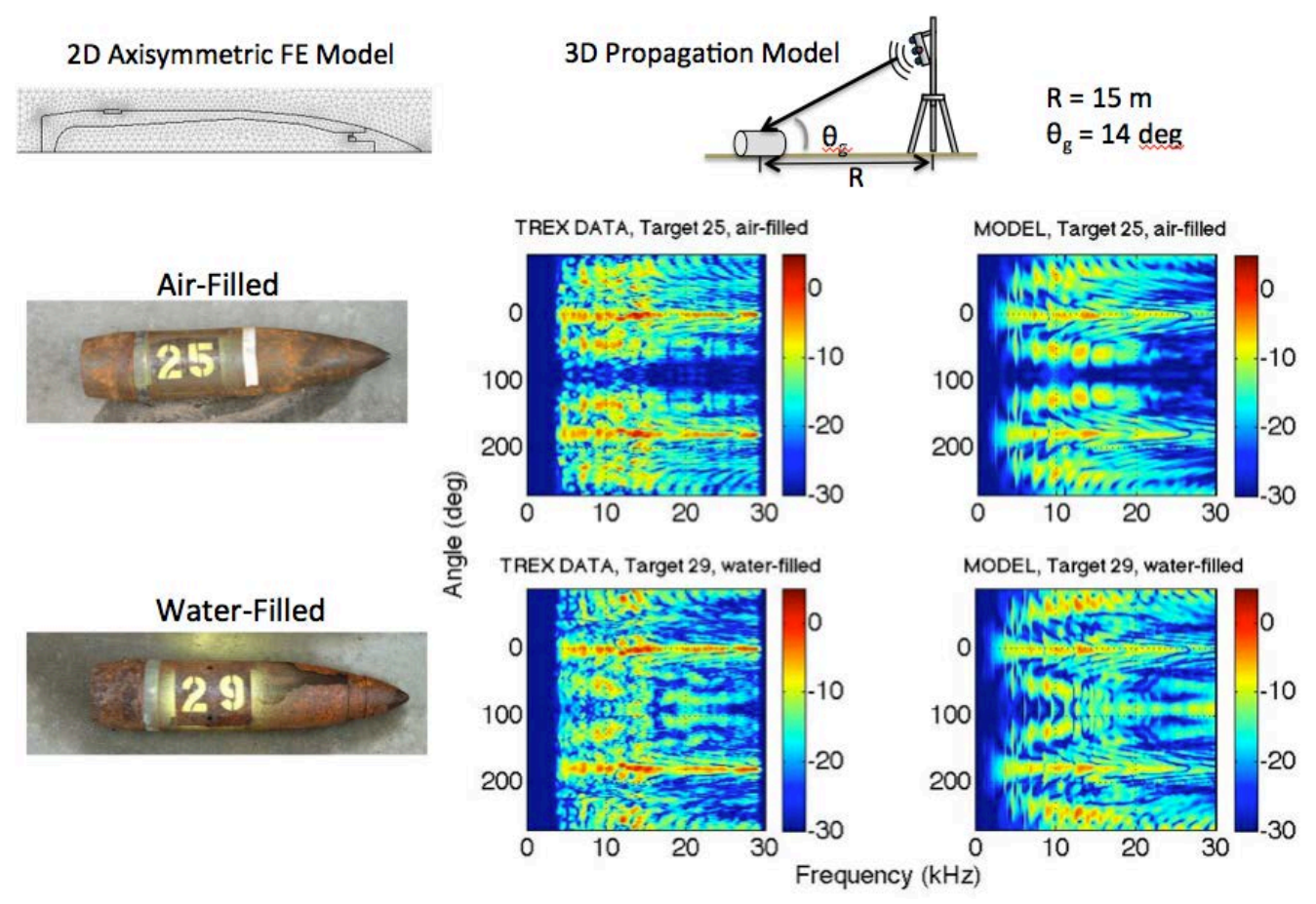

Figure 2. The geometry, finite element model, targets, experimental data and finite element model predictions are shown for 2 of the 27 targets used in TREX13.

Figure 2 shows details of the TREX13 geometry, the finite element mesh and the experiment and modeling results for two of the 27 the targets deployed during TREX13. The two targets are identical in shape but one is internally flooded with water while the other contains air.

The experiment and modeling results are the absolute target strength as a function of angle (full 360 degrees) and frequency $(3-30 \mathrm{kHz})$. Both the experiment and model indicate that flooding the target with water causes the TS signature to change, especially near 90 degrees.

Several other targets in the experiment have been modeled and data/model comparisons indicate that the combination of finite element/physical acoustics modeling is able to capture many of the salient features of the experimental data. 

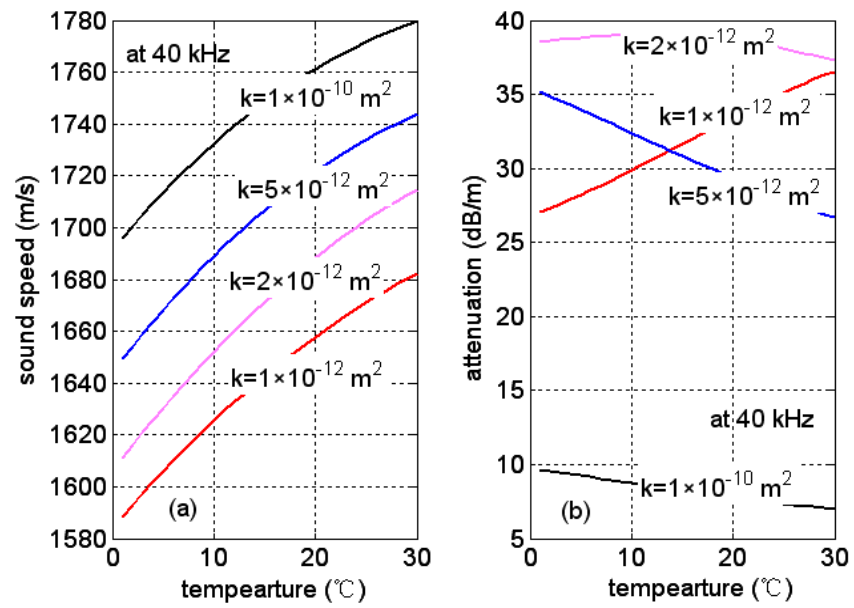

Fig. 3. Sound speed and attenuation (at $40 \mathrm{kHz}$ ) vs. temperature below, near, and above the attenuation transition permeability $\left(k_{a t}\right)\left(k_{a t}\right.$ is approximately $2 \times 10^{-12}$ for the case chosen).
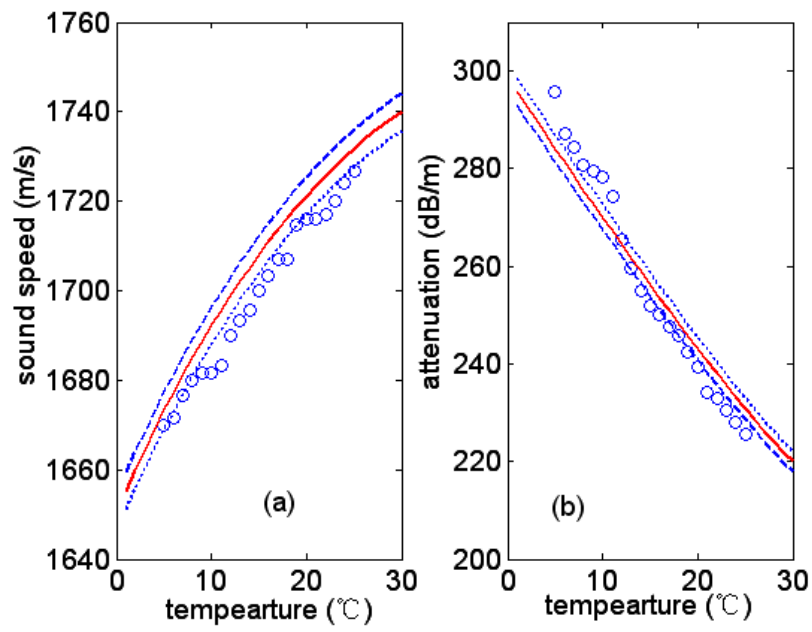

Figure 4. Comparisons of acoustic experiment data (circles, which are extracted from Figs. 3 and 4 of [4]) with theoretical calculations using EDFM for (a) sound speed and (b) attenuation vs. temperature.

Figure 3 shows the predicted sound speed and attenuation in a sand sediment as a function of temperature for different values of permeability. (The permeability of sand sediment can range from $10^{-13}$ to $10^{-10} \mathrm{~m}^{2}$.) Sound speed behaves similarly at all permeabilities shown, however, and behavior of the attenuation as a function of temperature can be very different for different permeabilities. The physics behind the behavior of attenuation is explained in [1]. The model used in [1] (and in Fig. 3) is the simplification of the Biot porous medium model known as the EDFM [2]. Figure 4 shows data/model comparisons presented in [1] indicating the viability of the EDFM for capturing the overall temperature dependence of sand sound speed and attenuation. 


\section{IMPACT/APPLICATIONS}

Active ASW and MCM at mid-frequencies (1-10 kHz) is a mainstay of the US Navy. Modeling to predict Signal-to-Noise ratios and target signatures in the Ocean are thus of primary importance. The results of the modeling carried out and the experimental validation of these models can feed directly into the next generation of Navy models used in TDAs and mission planning tools.

\section{RELATED PROJECTS}

"High Fidelity Finite Element Modeling for the Identification of Low- to Mid-Frequency Proud and Buried Object Elastic Responses and SAS Image Features," ONR Grant \#: N62909-10-1-7153, PI: M. Nijhof

"Acoustic Color of mines and mine-like objects: Finite Element Modeling (FEM), Developing Automatic Target Recognition (ATR) strategies, and at-sea experimental validation," ONR Contract \#: N00014-07-G-0557/0032, PI: K. L. Williams (APL-UW).

"Full Scale Measurement and Modeling of the Acoustic Response of Proud and Buried Munitions at Frequencies from 1-30 kHz,” SERDP Contract \#: W912HQ-09-C-0027, PI: S. G. Kargl

\section{REFERENCES}

1. D. Zou, K. L. Williams and E. I. Thorsos, “The Influence of Temperature on the Acoustic Sound Speed and Attenuation of Seafloor Sand Sediment," under review by IEEE J. Ocean. Eng.

2. K. L. Williams, "Adding thermal and granularity effects to the effective density fluid model," $J$. Acoust. Soc. Am., 133, EL431-437 (2013).

3. R. Carbó and A. C. Molero, "The effect of temperature on sound wave absorption in a sediment layer," J. Acoust. Soc. Amer., Vol. 108, no. 4, pp. 1545-1547, 2000.

\section{PUBLICATIONS}

1. L. Espana, K. L. Williams, D. S. Plotnick, P. L. Marston, “Acoustical Scattering from a waterfilled cylindrical shell: Measurements, modeling and interpretation, J. Acoust. Soc. Am. 136 , 109 (2014);

2. Zou, K. L. Williams and E. I. Thorsos, “ The Influence of Temperature on the Acoustic Sound Speed and Attenuation of Seafloor Sand Sediment," accepted for publication in IEEE J. Ocean. Eng. 